\title{
Diminished concentrations of insulin-like growth factor I in cystic fibrosis
}

\author{
E M Laursen, A Juul, S Lanng, N Høiby, C Koch, J Müller, N E Skakkebæk
}

\begin{abstract}
Cystic fibrosis is frequently accompanied by a catabolic condition with low body mass index caused by a number of disease complications. Insulin-like growth factor-I (IGF-I) is an anabolic hormone and an important marker of nutritional status, liver function, and linear growth. Available data on IGF-I in cystic fibrosis are sparse and conflicting. From 1990-3, 235 of our 240 patients (114 males, 121 females, median age $16 \cdot 2$ years, range $0 \cdot 1-44 \cdot 0$ years) had IGF-I measured once by radioimmunoassay. IGF-I was significantly reduced compared with a healthy Scandinavian control population: mean $(-2 \mathrm{SD}$ to $+2 \mathrm{SD})$ IGF-I SD score was $-0.97(-3.7$ to 1.7$)$ in males and $-0.67(-3.2$ to 1.9$)$ in females. Height SD score was $-0.95(-3.3$ to 1.4$)$ in males and $-0.81(-3.2$ to 1.6$)$ in females. In patients who were still in the growth period a significant correlation of IGF-I SD score to height SD score $(r=0.28, p<0.001)$ was found. The low IGF-I concentrations may reflect the catabolic state of many patients with cystic fibrosis and play a part in their abnormal growth pattern.

(Arch Dis Child 1995; 72: 494-497)
\end{abstract}

Keywords: cystic fibrosis, insulin-like growth factor.

Cystic fibrosis is the most common serious disease with autosomal recessive inheritance and the incidence in Denmark is $1: 4761 .^{1}$ In younger patients the disease is usually well controlled with intensive, prophylactic, antibiotic treatment and pancreatic enzyme substitution. However, with increasing age and progression of the lung disease, patients with cystic fibrosis experience increasing catabolic problems with loss of weight and decline in body mass index (BMI). Several reasons for this catabolic condition are obvious and include chronic pulmonary infection with Pseudomonas aeruginosa and other pseudomonas species, diabetes mellitus, and impairment of liver function.

Changes in the concentration of insulinlike growth factor-I (IGF-I) might play a part in patients with cystic fibrosis. IGF-I is an anabolic hormone that stimulates the formation of bone and cartilage, and has an insulin-like effect. ${ }^{2}$ The production of IGF-I takes place primarily in the liver, and the concentration in the blood is mainly regulated by growth hormone. However, other factors also play a part in the regulation including nutritional status, liver function, and concentrations of sex steroids. ${ }^{2}{ }^{3}$ Results of earlier studies on IGF-I in small groups of patients with cystic fibrosis have been conflicting as both normal and diminished concentrations have been reported. ${ }^{4-7}$ As the first step in the elucidation of the significance of IGF-I in cystic fibrosis, we performed a cross sectional study to determine the serum concentrations of IGF-I in a large, unselected population of patients and correlated the results to genotype and simple measures of growth, nutrition, pulmonary function, and liver function.

\section{Patients and methods}

Altogether $240(77 \%)$ of the 312 Danish patients with cystic fibrosis attend the Danish cystic fibrosis centre at Rigshospitalet. Approximately $80 \%$ are homozygous for delta F508 and $19 \%$ are compound heterozygous (delta F508/another mutation). During the period from 1990-3 serum IGF-I was measured in 235 patients (114 males, 121 females, median age $16 \cdot 2$ years, range $0 \cdot 1-44 \cdot 0$ years). IGF-I was measured in random fashion as an initial step in a larger ongoing prospective study on growth and development in patients with cystic fibrosis. Height, weight, forced expiratory vital capacity in one second $\left(\mathrm{FEV}_{1}\right)$, and forced vital capacity (FVC) were recorded as the mean of values obtained monthly during the year when the blood sample was drawn. Serum values of alkaline phosphatase, alanine aminotransferase, bilirubin, and coagulation factor II, VII, and X were obtained yearly on a routine basis and present values were registered within the last year. BMI was calculated as weight $(\mathrm{kg})$ divided by height (m) squared.

IGF-I was measured by radioimmunoassay on acid-ethanol extracted serum including a cryoprecipitation step using monoiodinated [125I] $\mathrm{Tyr}^{31}$-labelled des-(1-3)IGF-I as radioligand. Interassay and intra-assay variation was $8.7 \%$ and $3.9 \%$, respectively at bound/free ratio of $0 \cdot 4.8$

To correct for sex and age differences in height, BMI, and IGF-I, SD scores were calculated using sex and age specific means and SD values from the following equation: $(x-$ mean)/SD. The control group for IGF-I, height, and BMI consisted of 1030 normal healthy individuals previously described. ${ }^{8}$ Lung function was transformed to per cent predicted values $\left(\mathrm{FEV}_{1}\right.$ predicted and FVC predicted) using the standard formulas of Polgar and Promadhat. ${ }^{9}$
Laursen, Department of

Growth and Reproduch

Blegdamsvej 9, 2100

Copenhagen $\emptyset$, Denmark

Accepted 2 February 1995 
IGF-I SD score and height SD score in patients with cystic fibrosis; values are mean $(-2 S D$ to $+2 S D)$

\begin{tabular}{|c|c|c|c|c|c|c|c|c|}
\hline & \multicolumn{2}{|l|}{ All $(n=235)$} & \multicolumn{3}{|c|}{ Males: age in years $(n=114)$} & \multicolumn{3}{|c|}{ Females: age in years $(n=121)$} \\
\hline & Males & Females & $\leqslant 10$ & $>10-\leqslant 20$ & $>20$ & $\leqslant 10$ & $>10-\leqslant 20$ & $>20$ \\
\hline $\begin{array}{l}\text { IGF-I SD score } \\
\text { Height SD score }\end{array}$ & $\begin{array}{l}-0.97^{\star} \\
(-3 \cdot 7 \text { to } 1 \cdot 7) \\
-0.95^{\star} \\
(-2 \cdot 1 \text { to } 1 \cdot 4)\end{array}$ & $\begin{array}{l}-0.67^{\star} \\
(-3.2 \text { to } 1.9) \\
-0.81^{\star} \\
(-3.2 \text { to } 1 \cdot 6)\end{array}$ & $\begin{array}{l}-0.57^{\star} \\
(-2 \cdot 3 \text { to } 1 \cdot 1) \\
-1.04^{\star} \\
(-3.6 \text { to } 1.5)\end{array}$ & $\begin{array}{l}-1.37^{\star} \\
(-4 \cdot 2 \text { to } 1 \cdot 4) \\
-0.91^{\star} \\
(-3.3 \text { to } 1 \cdot 4)\end{array}$ & $\begin{array}{l}-0.69^{\star} \\
(-5.8 \text { to } 3.4) \\
-0.92^{\star} \\
(-3.1 \text { to } 1 \cdot 3)\end{array}$ & $\begin{array}{l}-0.13 \\
(-2.2 \text { to } 1.9) \\
-0.65^{\star \star} \\
(-3.2 \text { to } 1.9)\end{array}$ & $\begin{array}{l}-0.96^{\star} \\
(-3.1 \text { to } 1.2) \\
-0.84^{\star} \\
(-3.1 \text { to } 1.4)\end{array}$ & $\begin{array}{l}-0.84^{\star \star} \\
(-3.9 \text { to } 2 \cdot 2) \\
-0.90^{\star} \\
(-3.3 \text { to } 1.5)\end{array}$ \\
\hline
\end{tabular}

Different from zero: ${ }^{\star} \mathrm{p}<0.001 ;{ }^{\star \star} \mathrm{p}<0.01$.

\section{STATISTICS}

Statistical analyses were performed using a statistical package (SPSS/PC+). Student's $t$ test was used to determine whether SD score levels were significantly different from zero and whether differences between two groups were significant. Linear regression analysis was used to investigate the degree of correlation between variables. Multiple stepwise regression analysis was used to clarify the most important factors for the variation in IGF-I SD score.

\section{ETHICS}

The study was in accordance with the Helsinki II declaration and approved by the local ethics committee of Copenhagen, Denmark (approval No 01-008/93).

\section{Results}

IGF-I concentrations in the patients with cystic fibrosis were significantly lower than those in a healthy Scandinavian control population (table). In males, the IGF-I SD score was below the mean in $81 \%$ and below -2 SD in $18 \%$ (fig 1). In $69 \%$ of the females IGF-I SD score was below the mean and in $14 \%$ it was below -2 SD (fig 2). In all 235 patients with cystic fibrosis IGF-I SD score correlated negatively with age $(r=-0 \cdot 18, \mathrm{p}<0 \cdot 01)$. Height $\mathrm{SD}$ score was also reduced (table). In $75 \%$ the height SD score was below the mean and in

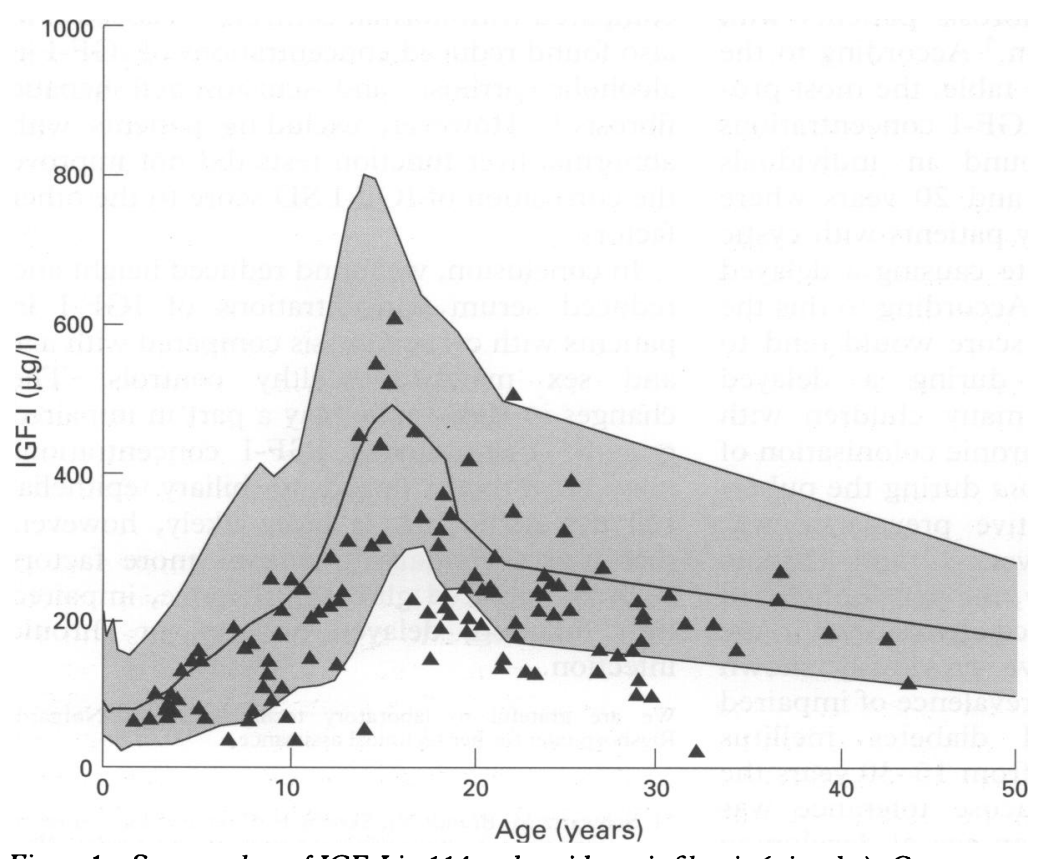

Figure 1 Serum values of IGF-I in 114 males with cystic fibrosis (triangles). Curves represent geometric mean (2SD) in normal controls. ${ }^{8}$ Shaded area represents normal range (2 SD).
$17 \%$ below -2 SD. IGF-I SD score in the 147 patients who were still in the growth period (males under 20 years and females under 18 years) showed significant correlation with the height SD score $(r=0.31, \mathrm{p}<0.001)$. BMI SD score was diminished but could only be calculated in 203 individuals from the age of 6 years as standards for Danish children under this age are not available. In males, mean $(-2 \mathrm{SD}$ to +2 SD) BMI SD score was -0.59 ( -3.2 to 2.02$)$, significantly different from zero $(p<0.05)$. In females, BMI SD score was $-0.69(-1.6$ to $1 \cdot 1)(p<0 \cdot 001)$. BMI SD score was lower in females than in males $(p<0.001)$ and IGF-I SD score and BMI SD score were significantly correlated $(r=0 \cdot 18, \mathrm{p}<0 \cdot 012)$.

The lung function in the whole population expressed by $\mathrm{FEV}_{1}$ predicted and FVC predicted was reduced. Children younger than 5-6 years could not cooperate with measurements of $\mathrm{FEV}_{1}$ and FVC and lung function was measured in only 205 individuals. Mean ( -2 $\mathrm{SD}$ to $+2 \mathrm{SD}) \mathrm{FEV}_{1}$ predicted was $67 \%$ $(15-120 \%)$ in males and 64\% (19-109\%) in females whereas mean FVC predicted was $91 \%$ $(42-140 \%)$ in males and $85 \%(47-124 \%)$ in females. Both lung function parameters were significantly different from $100 \%(p<0.001)$. Correlation analysis of the relation between IGF-I SD score and lung function revealed values of $r=0.10, \mathrm{p}<0.04$ and $r=0.15, \mathrm{p}<0.15$ for $\mathrm{FEV}_{1}$ predicted and FVC predicted, respectively.

We found significant lower concentrations of IGF-I in patients with cystic fibrosis with one or more abnormal liver function indices compared with those patients with normal liver function indices $(p<0 \cdot 04)$. However, omitting the 49 patients with one or more abnormal liver function test did not improve any of the correlations with age, height SD score, BMI SD score, lung function, or genotype. No significant difference was found between IGF-I concentrations in cystic fibrosis patients homozygous for delta F508 compared with those compound heterozygous for delta F508.

Finally, a multiple stepwise regression analysis with IGF-I SD score as the dependent variable and height SD score, BMI SD score, $\mathrm{FEV}_{1}$ predicted, FVC predicted, liver function, and genotype in the equation revealed that height SD score, liver indices, and FVC predicted correlated significantly with IGF-I SD score but accounted for only $12 \%$ of the variation in IGF-I SD score.

\section{Discussion}

Serum concentrations of the growth factor IGF-I were significantly diminished in this 


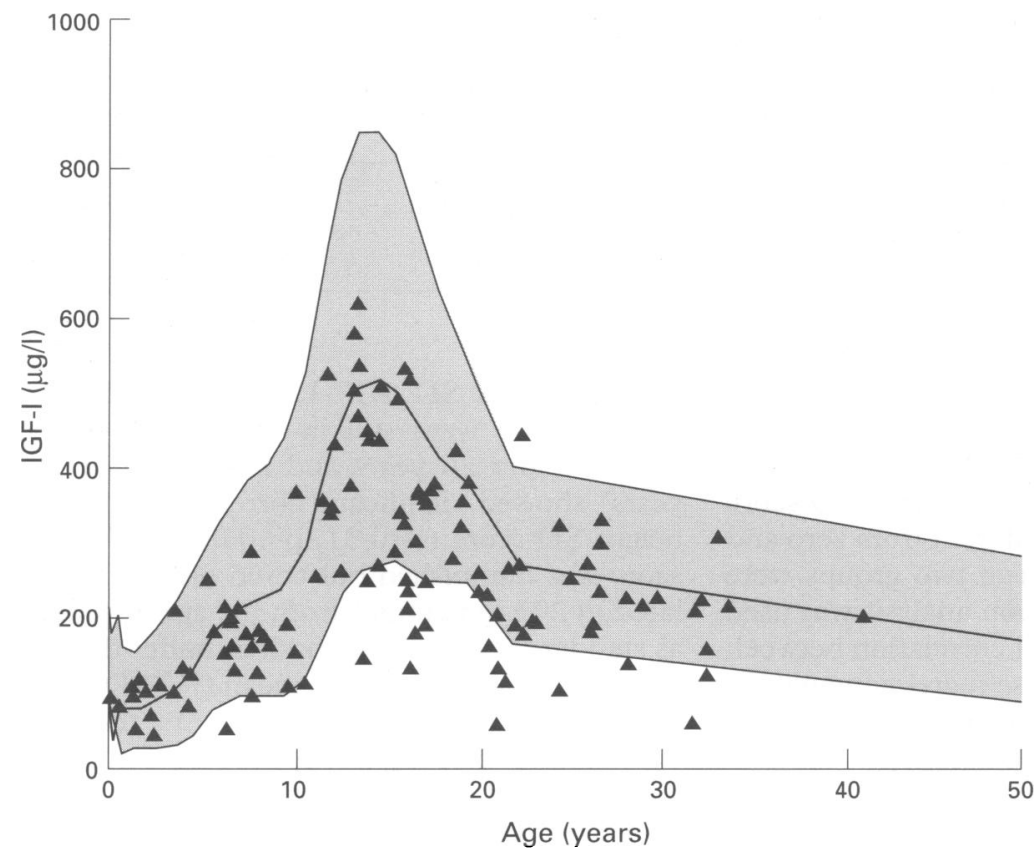

Figure 2 Serum values of IGF-I in 121 females with cystic fibrosis. Curves represent geometric mean (2SD) in normal controls. ${ }^{8}$ Shaded area represents normal range (2 SD).

group of patients with cystic fibrosis. Furthermore, as a group the cystic fibrosis patients were significantly growth retarded and $17 \%$ were below -2 SD for height. The correlation between IGF-I and height was significant but rather weak. However, this is also the case in normal controls, ${ }^{8}$ as short term changes may occur, for example, due to acute infections or decreased food intake. Previous studies in patients with cystic fibrosis have yielded conflicting results as three studies in 31,19 , and 15 patients, respectively, revealed normal concentrations of IGF-I compared with normal controls. 467 Furthermore, Rosenfeld et al found no correlation between IGF-I and height. ${ }^{7}$ In contrast, Lee et al showed a $50 \%$ decrease in IGF-I concentrations compared with normal controls in six cystic fibrosis patients with severe growth retardation. ${ }^{5}$ According to the age groups shown in the table, the most pronounced deviations in IGF-I concentrations in our study were found in individuals between the age of 10 and 20 years where peak values occur. Many patients with cystic fibrosis enter puberty late causing a delayed pubertal peak in IGF-I. According to this the reduction in IGF-I SD score would tend to be most pronounced during a delayed puberty. Furthermore, many children with cystic fibrosis develop chronic colonisation of the lungs with $P$ aeroginosa during the pubertal years. The cumulative prevalence was reported to be $50 \%$ between 11 and 12 years in our patients. ${ }^{10}$ Finally, the development of impaired glucose tolerance often occurs in the pubertal years. We have previously shown that the incidence and prevalence of impaired glucose tolerance and diabetes mellitus increased with age, and from $15-30$ years the decrease in normal glucose tolerance was almost linear. ${ }^{11}$ The mean age of developing diabetes mellitus in the Danish cystic fibrosis patients was 15 years in females and
22 years in males (Lanng et al, unpublished data).

The type of mutation in cystic fibrosis has some influence on the expression of the disease. ${ }^{10}$ The delta F508 mutation comprises $88 \%$ of Danish cystic fibrosis mutations which forms a rather uniform patient population ${ }^{1}$ and fat malabsorption was present in different degrees in the vast majority of our cystic fibrosis patients. ${ }^{12}$ Impaired nutritional status is known to be associated with lowering of IGF-I, ${ }^{2}$ and BMI SD score was reduced in the patients. However, BMI SD score only correlated weakly with IGF-I, indicating that malabsorption and insufficient energy intake were not responsible for the reduced IGF-I concentrations. Also Rosenfeld et al found no correlation of IGF-I with weight or nutritional status. ${ }^{7}$ Chronic and recurrent pulmonary infection and the subsequent decrease in pulmonary function lead to increased resting energy expenditure and weight loss, so the decline in BMI with age may be due to the progressive lung disease rather than being related to low IGF-I production. It is well known that the conventional liver function tests as used in this study do not express the degree of liver dysfunction in cystic fibrosis very well. ${ }^{13} 14$ The liver disease in cystic fibrosis is primarily caused by obstruction in the bile system leading to the characteristic macronodular cirrhosis, ${ }^{13} 15$ but no simple measure of the early stages of this process is available. However, we found lower concentration of IGF-I in cystic fibrosis patients with abnormal liver function tests. Accordingly, Schepper et al found in 31 cystic fibrosis patients that although IGF-I concentrations were normal there was a significant difference between patients with liver impairment compared with those without. ${ }^{4}$ Sheppard et al found that IGF-I concentrations were reduced to $30 \%$ in patients with primary biliary cirrhosis, primary sclerosing cholangitis and alcohol induced liver disease compared with normal controls. ${ }^{16}$ Assaad et al also found reduced concentrations of IGF-I in alcoholic cirrhosis and schistosomal hepatic fibrosis. ${ }^{17}$ However, excluding patients with abnormal liver function tests did not improve the correlation of IGF-I SD score to the other factors.

In conclusion, we found reduced height and reduced serum concentrations of IGF-I in patients with cystic fibrosis compared with age and sex matched healthy controls. The changes in IGF-I may play a part in impaired growth. The reduced IGF-I concentrations may be directly linked to biliary epithelial cell dysfunction. It is more likely, however, that it is secondary to one or more factors such as impaired glucose tolerance, impaired liver function, delayed puberty, or chronic infection.

We are grateful to laboratory technician Lena Nørgård, Rigshospitalet for her technical assistance.

1 Schwartz M, Brandt NJ, Skovby F. Screening for carriers of cystic fibrosis among pregnant women: a pilot study. Hum Genet 1993; 1: 239-44.

2 Canalis E. Clinical review 35: growth factors and their potential clinical value. $\mathcal{F}$ Clin Endocrol Metab 1992; 75: 1-4. 
3 Guler H, Zapf J, Froesch ER. Short-term effects of recombinant human insulin-like growth factor I in healthy binant human insulin-like growth factor

4 De Schepper J, Van Blerk M, Hachimi-Idrissi S, Dab L, Smitz J. Plasma insulin-like growth factor-1 determinations in patients with cystic fibrosis: influence of the nutritional and liver status. Clinical Nutrition 1992; 11: 298-302.

5 Lee JA, Dickinson LS, Kilgore BS, Warren RH, Elders MJ. Somatomedin activity in cystic fibrosis and reserpinized rats: possible explanation for growth retardation. Ann Clin Lab Sci 1980; 10: 227-33.

6 Pedersen PS, Kastrup KW. Somatomedin in cystic fibrosis. Acta Paediatr Scand 1983; 72: 757-8.

7 Rosenfeld RG, Landon C, Lewiston N, Nagashima R, Hintz BA, Hintz RL. Demonstration of normal somatomedin concentrations in cystic fibrosis. $f$ Pediatr 1981; 99: 252-4.

8 Juul A, Bang P, Hertel NT, et al. Serum insulin-like growth factor-I in 1030 healthy children, adolescents, and adults: relation to age, sex, stage of puberty, testicular size, and body mass index. F Clin Endocrinol Metab 1994; 78: 744-52.

9 Polgar G, Promadhat V. Pulmonary function testing in children: techniques and standards. Philadelphia: WB Saunders, 1971: 88-107, 178-82.

10 Johansen HK, Nir M, Høiby N, Koch C, Schwartz M.
Severity of cystic fibrosis in patients homozygous and heterozygous for delta F508 mutation. Lancet 1991; 337: heterozygo

11 Lanng S, Thorsteinsson B, Erichsen G, Nerup J, Koch C. Glucose tolerance in cystic fibrosis. Arch Dis Child 1991; 66: 612-6.

12 Lanng S, Schwartz M, Thorsteinsson B, Koch C. Endocrine and exocrine pancreatic function and the delta F508 mutation in cystic fibrosis. Clin Genet 1991; 40 345-8.

13 Colombo C, Apostolo MG, Assaisso M, Roman B, Bottani P. Liver disease in cystic fibrosis. Neth 7 Med 1992; 41: 119-22.

14 Williams SGJ, Westaby D, Tanner MS, Mowat AP. Liver and biliary problems in cystic fibrosis. $\mathrm{Br}$ Med Bull 1992; 48: 877-92.

15 Nagel RA, Javaid A, Meire HB, et al. Liver disease and bileduct abnormalities in adults with cystic fibrosis. Lancet 1989; ii: 1422-5.

16 Sheppard MS, Minuk GY, Bhaumick B, Bala RM. Insulinlike growth factors (IGF) in liver disease: differential changes of IGF-I and IGF-II. Clin Invest Med 1987; 10: 49-53.

17 Assaad SN, Cunningham GR, Samaan NA. Abnormal growth hormone dynamics in chronic liver disease do not depend on severe parenchymal disease. Metabolism 1990; 39: $349-56$. 